\title{
EDITORIAL
}

\section{Improving survival in pulmonary arterial hypertension}

\author{
M. Humbert
}

$\mathbf{M}$ ore than 50 yrs ago, DRESDALE et al. [1] reported a series of 39 patients with unexplained pulmonary hypertension and coined the term "primary pulmonary hypertension" to describe the condition, a term that has been revised to "idiopathic pulmonary arterial hypertension" in the most recent classification [2]. Idiopathic pulmonary arterial hypertension is a disease of the small pulmonary arteries, which leads to a progressive increase in pulmonary vascular resistance, ultimately causing right ventricular failure and death [3,4]. Despite major advances in the understanding of the pathobiology of pulmonary arterial hypertension, none of the current therapeutic approaches achieves a cure for this devastating condition $[5,6]$.

Survival has been extensively studied in idiopathic pulmonary arterial hypertension [7]. An American registry supported by the National Institute of Health (NIH) was begun in 1981 to collect data from 32 centres on patients diagnosed by uniform criteria as having so-called primary pulmonary hypertension [7, 8]. Between July 1, 1981 and September 30, 1985, 194 patients were entered into the $\mathrm{NIH}$ registry, providing the first multicentre, detailed clinical and haemodynamic description of this disease $[7,8]$. This pioneer study allowed analysis of the survival and prognosis factors [7]. As of August 1988, 106 of the 194 patients had died (mostly of right-heart failure and sudden death), emphasising the dismal prognosis of this condition [7]. A total of 13 patients who had heart-lung transplant were followed only to the time of transplant, and 15 patients lost to follow-up were considered to be survivors, for purposes of the analysis [7]. The estimated median survival from baseline catheterisation was $2.8 \mathrm{yrs}$, with estimated single-year survival rates at 1,3 , and $5 \mathrm{yrs}$ of 68,48 , and $34 \%$, respectively [7]. Poor survival was associated with a New York Heart Association (NYHA) functional class III or IV, and independent haemodynamic variables, i.e. elevated mean right atrial pressure, elevated mean pulmonary artery pressure and decreased cardiac index [7]. Thus, the main conclusion of the $\mathrm{NIH}$ registry was that mortality correlated with indices of right ventricular haemodynamic function [7]. A regression equation was then developed to describe the relationship between these three haemodynamic variables and mortality [7]. This equation

CORRESPONDENCE: M. Humbert, Service de Pneumologie, Hôpital Antoine-Béclère, 157 Rue de la Porte de Trivaux, 92140 Clamart, France. Fax: 33 146303824. E-mail: marc.humbert@abc.aphp.fr

M. Humbert is supported by grants from Université Paris-Sud (Paris, France), Legs Poix (Paris, France), Institut National de la Santé et de la Recherche Médicale (Paris, France) and Association Française contre les Myopathies (Evry, France). M. Humbert has relationships with drug companies including Actelion, Aventis, Boehringer Ingelheim, Encysive, GlaxoSmithKline, Myogen, Schering, Pfizer and United Therapeutics. In addition to being an investigator in trials involving these companies, these relationships include consultancy services and membership of scientific advisory boards. that was used to predict a patient's chance of survival was later validated in an independent series of patients [9]. No drug therapy at entry or discharge was associated with survival duration in the NIH registry, presumably because no effective treatments of the disease were available at that time [7]. Therefore, it is widely assumed that survival in the NIH registry reflects the natural history of the untreated disease. Fortunately, in fewer than 20 yrs, these patients have gone from a state of no hope to one where prolonged survival and improvements in quality of life can be achieved thanks to novel therapeutic agents, including prostacyclin derivatives, endothelin receptor antagonists and type- 5 phosphodiesterase inhibitors [6].

Continuous i.v. epoprostenol has been the only drug to demonstrate improved survival in the setting of a prospective, randomised, open trial in idiopathic pulmonary arterial hypertension [10]. This study was conducted in 81 NYHA functional class III or IV patients who were randomly assigned to receive either conventional therapy alone (including warfarin, diuretics, oxygen and oral vasodilators) or therapy with i.v. epoprostenol infusion [10]. After 12 weeks, epoprostenol therapy was associated with an improved 6-min walk distance and a significant improvement in survival; eight patients in the conventional therapy group died during the study, whereas no death occurred in the epoprostenol group [10]. The $20 \%$ mortality rate observed at 12 weeks in the placebo group is much higher than what is currently observed in controlled studies [11]. This is simply explained by the fact that investigators no longer include the most severe patients in placebo-controlled trials and, appropriately, choose to treat them with first-line active therapy. Therefore, in recent years, the question of the most relevant surrogate marker of mortality in placebo-controlled trials has been the topic of intense discussion [6]. The 6-min walk test is a safe and highly reproducible submaximal exercise test, which can be performed by patients who are incapable of tolerating maximal exercise testing [12]. The distance walked in $6 \mathrm{~min}$ has a strong, independent association with mortality in patients with idiopathic pulmonary arterial hypertension and, therefore, represents an excellent surrogate marker of mortality [12]. Another way to approach the survival effects of novel agents is represented by the analysis of long-term mortality in cohorts of treated patients. Cohort analysis of patients receiving continuous i.v. epoprostenol, as compared with historical control groups or the NIH-predicted survival, clearly demonstrated survival benefits in NYHA functional class III and IV patients $[13,14]$. A recent study showed that i.v. epoprostenol improved survival in 178 patients with idiopathic pulmonary arterial hypertension in comparison with historical controls (1-, $2-, 3-$ and 5-yr survival rates are 85, 70, 63 and 55\%, 
respectively, as compared with 58, 43,33 and $28 \%$ for historical controls $(p<0.0001)$ ) [13]. Another cohort of 162 epoprostenoltreated patients confirmed improved survival, as compared with that calculated using the NIH equation [14].

Two double-blind, randomised, placebo-controlled trials have evaluated the efficacy of bosentan, an orally active, dual endothelin-receptor antagonist, in patients with pulmonary arterial hypertension (idiopathic or that associated with scleroderma) [15, 16]. Clinical, functional and haemodynamic improvements were demonstrated, although survival was not improved in these 16-week studies that mostly focused on NYHA functional class III patients $[15,16]$. In this issue of the European Respiratory Journal, MCLAUGHLIN et al. [17] report novel information on the long-term survival of the patients with idiopathic pulmonary arterial hypertension receiving first-line bosentan therapy in these two studies and their extension $[15,16]$. Interestingly, these data indicate that using first-line bosentan, followed by additional therapy if needed, improved survival, as compared with what was expected based on the NIH equation (observed 1- and 2-yr survival were 96 and $89 \%$, as compared with an estimated survival of 69 and $57 \%$, respectively) [17]. As stated by the authors, this study has several limitations. Presumably, subjects selected for randomised studies have a better general condition and standard of care than patients treated $20 \mathrm{yrs}$ ago. Therefore, survival estimated in the 1980s with the NIH equation is certainly a pessimistic comparator. Nevertheless, the NIH equation has been validated and still represents the best available tool for comparative studies. First-line bosentan therapy does not mean bosentan-only therapy, and there is indeed a population who fail to respond to this agent and are subsequently treated with other drug(s). However, at 1 and 2 yrs, 85 and $70 \%$ of the patients remained alive and on bosentan only, indicating that survival improvement at 2 yrs is obtained with monotherapy in a majority of cases [17]. Add-on or switch to another class of drug has to be further evaluated, in order to better understand clinical, haemodynamic and functional characteristics of the patients who will benefit from these second-line strategies, and those who will not and should, therefore, be considered for lung transplantation [6, 18]. Drug exposure is rather short in this study [17], and longer-term information will be of interest to determine whether add-on or switch to another class of drug is required in the long term and what the exact prognosis of these patients is. Lastly, $\geqslant 50 \%$ of patients treated in pulmonary vascular centres display "nonidiopathic" pulmonary arterial hypertension $[2,19]$. In these patients, the outcome of the disease has been less well characterised than in patients with idiopathic pulmonary arterial hypertension [20]. Therefore, conclusions that have been drawn about idiopathic pulmonary arterial hypertension need to be further tested in other variants of the disease [20].

MCLAUGHLIN et al. [17] report that predictors of worse outcome at baseline included NYHA functional class IV and lower 6min walk distance. In these most severe patients, first-line therapy with bosentan may be regarded as controversial, and many experts consider first-line epoprostenol to be the best choice [6, 21]. First-line epoprostenol plus bosentan combination therapy has also been recently proposed in severe cases, but additional information is necessary to better determine the risks and benefits of combination therapy in these patients
[21-23]. In addition, survival effects of type-5 phosphodiesterase inhibitors alone or in combination with other agents will also have to be properly evaluated in future studies [21, 24]. Lastly, the prognosis according to the clinical and haemodynamical response to first-line bosentan therapy should be properly evaluated. Indeed, cohorts of epoprostenol-treated patients have demonstrated that patients whose symptoms improved sufficiently to permit reclassification to NYHA functional class I or II after 3 months on epoprostenol had a marked survival advantage [13]. Similarly, the absolute value of the 6-min walk distance after 3 months of therapy was a significant prognostic factor $[13,14]$. Obtaining similar information in bosentan-treated subjects would help towards the elaboration of updated therapeutic guidelines [21].

Several treatments for pulmonary arterial hypertension are now approved in North America (epoprostenol, treprostinil and bosentan) and Europe (epoprostenol, iloprost and bosentan) [6]. With the exception of recent data from patients receiving prolonged epoprostenol therapy and the present report by MCLAUGHLIN et al. [17], long-term effects of novel treatments are still unknown [13, 14]. There is a substantial need for long-term observational studies that evaluate the different treatments, in terms of survival, side-effects, quality of life and costs. As head-to-head comparisons of currently approved therapies are not available, the choice of optimal treatment will be dictated by clinical experience and drug availability, as well as patient preference [6]. In the future, the head-to-head comparison of first-line therapies will have to be performed in order to provide evidence-based guidelines in pulmonary arterial hypertension.

\section{REFERENCES}

1 Dresdale DT, Schultz M, Michtom RJ. Primary pulmonary hypertension. I. Clinical and hemodynamic study. Am J Med 1951; 11: 686-705.

2 Simonneau G, Galiè N, Rubin LJ, et al. Clinical classification of pulmonary hypertension. J Am Coll Cardiol 2004; 43, Suppl. 12, 5S-12S.

3 Rubin LJ. Primary pulmonary hypertension. N Engl J Med 1997; 336: 111-117.

4 Runo JR, Loyd JE. Primary pulmonary hypertension. Lancet 2003; 361: 1533-1544.

5 Humbert M, Morrell NW, Archer SL, et al. Cellular and molecular pathobiology of pulmonary arterial hypertension. J Am Coll Cardiol 2004; 43: Suppl. 12, 13S-24S.

6 Humbert M, Sitbon O, Simonneau G. Treatment of pulmonary arterial hypertension. N Engl J Med 2004; 351: 1425-1436.

7 D'Alonzo GE, Barst RJ, Ayres SM, et al. Survival in patients with primary pulmonary hypertension. Results from a national prospective registry. Ann Intern Med 1991; 115: 343-349.

8 Rich S, Dantzker DR, Ayres SM, et al. Primary pulmonary hypertension: a national prospective study. Ann Intern Med 1987; 107: 216-223.

9 Sandoval J, Bauerle O, Palomar A, et al. Survival in primary pulmonary hypertension: validation of a prognostic equation. Circulation 1994; 89: 1733-1744. 
10 Barst RJ, Rubin LJ, Long WA, et al. A comparison of continuous intravenous epoprostenol (prostacyclin) with conventional therapy for primary pulmonary hypertension. N Engl J Med 1996; 334: 296-302.

11 Galiè N, Manes A, Branzi A. The new clinical trials on pharmacological treatment in pulmonary arterial hypertension. Eur Respir J 2002; 20: 1037-1049.

12 Miyamoto S, Nagaya N, Satoh T, et al. Clinical correlates and prognostic significance of six-minute walk test in patients with primary pulmonary hypertension: comparison with cardiopulmonary exercise testing. Am J Respir Crit Care Med 2000; 161: 487-492.

13 Sitbon O, Humbert $\mathrm{M}$, Nunes $\mathrm{H}$, et al. Long-term intravenous epoprostenol infusion in primary pulmonary hypertension: prognostic factors and survival. I Am Coll Cardiol 2002; 40: 780-788.

14 McLaughlin VV, Shillington A, Rich S. Survival in primary pulmonary hypertension: the impact of epoprostenol therapy. Circulation 2002; 106: 1477-1482.

15 Channick RN, Simonneau G, Sitbon O, et al. Effects of the dual endothelin-receptor antagonist bosentan in patients with pulmonary hypertension: a randomised placebocontrolled study. Lancet 2001; 358: 1119-1123.

16 Rubin LJ, Badesch DB, Barst RJ, et al. Bosentan therapy for pulmonary arterial hypertension. N Engl J Med 2002; 346: 896-903.
17 McLaughlin VV, Sitbon O, Badesch DB, et al. Survival with first-line bosentan in patients with primary pulmonary hypertension. Eur Respir J 2005; 25: 244-249.

18 Pielsticker EJ, Martinez FJ, Rubenfire M. Lung and heartlung transplant practice patterns in pulmonary hypertension centers. J Heart Lung Transplant 2001; 20: 1297-1304.

19 Humbert M, Chaouat A, Bertocchi M, et al. ItinerAIRHTAP: a French national prospective registry of pulmonary arterial hypertension. Am J Respir Crit Care Med 2004; 169: A169.

20 McLaughlin VV, Presberg KW, Doyle RL, et al. Prognosis of pulmonary arterial hypertension: ACCP evidence-based clinical practice guidelines. Chest 2004; 126: Suppl. 1, 78S-92S.

21 Badesch DB, Abman SH, Ahearn GS, et al. Medical therapy for pulmonary arterial hypertension: ACCP evidencebased clinical practice guidelines. Chest 2004; 126: Suppl. 1, 35S-62S.

22 Humbert M, Barst RJ, Robbins I, et al. Combination of bosentan with epoprostenol in pulmonary arterial hypertension: BREATHE-2. Eur Respir J 2004; 24: 353-359.

23 Hoeper MM, Dinh-Xuan AT. Combination therapy for pulmonary arterial hypertension: still more questions than answers. Eur Respir J 2004; 24: 339-340.

24 Prasad S, Wilkinson J, Gatzoulis MA. Sildenafil in primary pulmonary hypertension. N Engl J Med 2000; 343: 1342. 